DOI 10.37882/2223-2982.2022.01.20

\title{
ИНТЕРНЕТ-ТЕХНОЛОГИИ: РЕШЕНИЯ ДЛЯ ДИСТАНЦИОННОГО ОБРАЗОВАНИЯ
}

\section{INTERNET TECHNOLOGIES: SOLUTIONS FOR DISTANCE EDUCATION}

\section{E. Nelyubina \\ Ya. Ulyanova \\ D. Minakov \\ A. Govorov}

Summary: Naturally, in the era of digitalization, educational institutions were forced to switch to a distance learning format, for which not all participants in the educational process were ready. However, the Internet, unlike the participants, was better prepared for the transition: online schools and online courses, services for organizing video calls and video broadcasts, electronic tests and textbooks, virtual classrooms and whiteboards, and so on, began to actively appear and develop. The digitalization of education has developed so widely and quickly that teachers with methodologists are simply doomed to spend on finding and studying solutions for organizing the process of distance learning, the results of which will be close to the results of face-to-face studies, time close to the duration of mastering their profession.

Purpose - development of methodological recommendations for conducting classes in chemistry in a distance format using modern Internet technologies.

Results: in the course of the work, means were selected for organizing a distance educational process that satisfy the methodological and technical requirements for conducting chemistry classes, Internet resources and web applications aimed at studying chemistry.

Keywords: methods of teaching chemistry, lesson, web applications, Internet resources.

\author{
Нелюбина Елена Георгиевна \\ К.п.н., дочент, ФГБОУ ВО «Самарский государственный \\ социально-педагогический университет», г. Самара \\ nelubina.elena@pgsga.ru \\ Ульянова Яна Александровна \\ ФГБОУ ВО «Самарский государственный социально- \\ педагогический университет», г. Самара \\ ulyanova.yana@sgspu.ru \\ Минаков Дмитрий Александрович \\ ФГБОУ ВО «Самарский государственный социально- \\ педагогический университет", г. Самара \\ minakov.dmitriy@sgspu.ru \\ Говоров Алексей Андреевич \\ ФГБОУ ВО «Самарский государственный сочиально- \\ педагогический университет», г. Самара \\ govorov.aleksey@sgspu.ru
}

Аннотация: Естественно, в эпоху цифровизации, образовательные учреждения были вынуждены перейти на дистанционный формат обучения, к которому, не все участники образовательного процесса были готовы. Однако интернет, в отличие от участников, к переходу был подготовлен лучше: стали активно появляться и развиваться онлайн-школы и онлайн-курсы, сервисы по организации видеозвонков и видеотрансляций, электронные тесты и учебники, виртуальные классы и доски, и так далее. Цифровизация образования развернулась так широко и быстро, что педагоги с методистами просто обречены потратить на поиск и изучение решений организации процесса дистанционного обучения, результаты которого будут близки к результатам очных занятий, время, близкое к длительности овладения своей профессией. Цель исследования: разработка методических рекомендаций проведения занятий по химии в дистанционной формате с применением современных интернет-технологий.

Результаты: в ходе работы подобраны средства для организации дистанционного образовательного процесса, удовлетворяющие методические и технические требования к проведению занятий по химии, Интернет-ресурсы и веб-приложения направленные на изучение химии.

Ключевые слова: методика обучения химии, урок, веб-приложения, Интернет-ресурсы.

и гимназии с университетами, в которых изучались латынь, немецкий, французский языки, история и география. Спустя век начали появляться приходские и уездные училища. [3] С появлением Советского Союза, была принята декларация о единой трудовой школе, обучение стало двухступенчатой, а начальное звено образования ᄀ- обязательным. Позднее, среднее образование также стало обязательным, а обучение длиться 11 лет. Со стартом нового тысячелетия введено положение о едином государственном экзамене, проведена реформа образования, а к 2019 году случилась пандемия. 


\section{Методические и технические требования}

В соответствии с требованиями ФГОС основного общего образования от 17.12.2010 № 1897 (ред. от 11.12.2020) [6] к информационно-методическим условия реализации основной образовательной программы общего образования должны обеспечиваться современные процедуры создания, поиска, сбора, анализа, обработки, хранения и представления информации. В связи с этим, можно сформулировать одно из технических требований к разработке модели дистанционного образовательного процесса занятия по химии: все участники данного процесса должны иметь при себе электронное устройство, имеющее доступ в интернет. Это может быть как персональный компьютер или ноутбук, так и мобильное устройство, здесь всё упирается в комфортность личного использования и финансовые возможности. [4, 5] Требования к техническим возможностям устройства разнятся и педагогу следует заранее предусмотреть возможности взаимодействия с тем или иным интернетресурсом для обеспечения дистанционного взаимодействия всех учеников образовательного процесса.

\section{Он^айн-учебники и теоретические материал}

Педагогу следует обеспечить всех учеников информационной поддержкой, а также учебниками по своему предмету. В рамках нашей модели можно выделить:

Для поиска электронной версии учебников, используемых непосредственно на очных занятиях, можно воспользоваться следующими сервисами:

1. Образовательная платформа Lecta от корпорации "Российский учебник" предоставила доступ к 693 электронным учебникам по коду УчимсяДома. Также есть платные тренажеры для самопроверки знаний. [https://lecta.rosuchebnik.ru/]

2. Издательство «Просвещение» дает возможность использовать электронные учебники по всем предметам целых 3 месяца. Вот инструкция по регистрации и работе с ЭФУ. [https://media.prosv.ru/] [https://media.prosv.ru/ static/files/Mediateka_UserGuide.pdf]

3. Издательство «Русское-слово» открыло доступ к Электронной образовательной среде, основа которой - электронный учебник с возможностью добавления проверочных материалов и отслеживания успеваемости учеников. Для подключения школы требуется заполнение данной формы. [https://русскоеслово.pф/articles/81757/] [https://forms.yandex.ru/ u/5e6f667c2f089d0b3be3ed6a/]

\section{Он^айн-учебники м^я организачии внеурочной и внеклассной работы.}

1. «Фоксфорд.Учебник» [https://foxford.ru/wiki] Собственная википедия «Фоксфорда»: Мы собрали всю школьную программу и немного больше в лаконичную структуру из отдельных статей. В учебнике есть понятные иллюстрации, видео-тьюториалы, возможность сохранять избранные статьи и много другое. И так по всем предметам - не только по химии.

2. «Учебник по неорганической химии» [https:// ido.tsu.ru/schools/chem/data/res/neorg/uchpos/] Справочник, который в 2006 году выпустил Томский государственный университет. «Неорганическая химия» - базовый раздел, с которого начинается изучение химии в восьмом классе, поэтому ресурс пригодится для подготовки к ОГЭ, ЕГЭ и олимпиадам.

3. Учебник по органической химии. [http:// orgchem.ru/] Больше нужен участникам олимпиад и старшеклассникам, которые готовятся к ЕГЭ: органическая химия начинается только в конце девятого класса. Однако в ОГЭ есть один вопрос из органики, поэтому девятиклассникам учебник тоже пригодится.

4. Учебник по истории химии [http://physchem. chimfak.sfedu.ru/Source/Files/sketch.pdf] Сборник авторских лекций, которые подготовил профессор Южного федерального университета Сергей Иванович Левченков. Отличный ресурс для того, чтобы понять логику науки: в какой последовательности происходили самые важные открытия в химии и как они связаны между собой.

\section{Практические работы м^я закрепления знаний}

1. Онлайн-портал «Химик» [http://www.xumuk.ru/] Химическая википедия. Этому ресурсу можно доверять, потому что разработчики перевели в электронный вид хорошие справочники по химии. Также они сделали удобный поиск по сайту. Ещё одно преимущество «Химика» - сервисы, которые помогают школьникам разобраться в сложных темах с помощью наглядных схем. Вот два самых важных из них:

«Электронное строение атома» - приложение для проверки своих знаний по строению атома: вводите символ элемента и приложение сразу выдаёт все возможные записи электронной конфигурации его атома.

«Поиск неорганических реакций» - сервис помогает разобраться, какие вещества реагируют друг с другом, при каких условиях и что образуется в результате. Например, если ввести в строку поиска уравнение $\mathrm{Cl} 2+$ $\mathrm{NaOH}$, можно получить все возможные реакции этих со- 
единений с коэффициентами.

2. Интерактивный тренажёр по уравниванию реакций [https://phet.colorado.edu/sims/html/balancingchemicalequations/latest/balancing-chemical-equations_ en.html] Уравнивание химических уравнений - один из важных навыков, которые важно освоить на начальном этапе изучения химии. Ресурс можно добавить в закладки на телефоне и тренироваться, когда появляется свободное время.

\section{^абораторные работы и виртуальные ^аборатории}

1. VirtuLab [http://www.virtulab.net/] Российский портал, на котором эксперименты из школьной программы можно смоделировать онлайн.

2. Labster [https://www.labster.com/] Международный ресурс, которые разрабатывают учёные со всего мира. Позволяет ставить более серьёзные опыты.

3. Mel Science [https://melscience.com/ru/] Проект по доставке на дом наборов для экспериментов. Также на сайте есть подробные и корректные инструкции по выполнению опытов. Многие ингредиенты для этих опытов можно самостоятельно купить в аптеке или продовольственном магазине. В дополнение к опытам на Mel Science полезно смотреть видео, которые объясняют суть химических явлений.

4. Занимательная химия [https://www.alto-lab.ru/] На портале есть множество полезных статей, подробные разборы опытов, инструкции, как проводить их в домашних условиях и где брать для них реактивы.

\section{$\triangle$ Аполнительные материалы мия самостоятельного ознакомления}

1. Постнаука. Химия [https://postnauka.ru/themes/ chemistry] Постнаука - проект о современной фундаментальной науке. На портале есть отдельный раздел, посвящённый химии. Здесь есть интервью известных учёных, научно-популярные статьи и подробные разборы как работают химические процессы.

2. Простая наука [https://www.youtube.com/user/ GTVscience/featured]

Канал на видеохостинге YouTube с химическими опытами и экспериментами.

3. Thoisoi [https://www.youtube.com/channel/ UCjAmQ-4NL3UZX0W_nmjn4_w] Тоже канал YouTube c опытами по всем разделам химии. Автор не только снимает зрелищные опыты, но и подробно объясняет суть наблюдаемых явлений. Также он показывает, с какими сложностями столкнулся при проведении эксперимента и рассказывает, почему произошла неудача.

4. Химия-Просто [https://www.youtube.com/ channel/UCRzZSz5JISfN6Ba164vqVCg] Ещё один канал видеохостинга YouTube с большим количеством роликов, посвящённых конкретным элементам и их соединениям. Автор канала Александр Иванов рассказывает об основных химических особенностях веществ и показывает опыты с ними.

\section{Работа с файлами}

Помимо образовательных сервисов в дистанционном образовании присутствуют формы работы с графиками, текстом, наглядными презентациями. Для таких форм работы используются специализированные приложения. Они представлены как отдельными приложениями, так и пакетами приложений от нескольких компаний:

1. Microsoft Office 365 [https://www.microsoft.com/ ru-ru/microsoft-365/free-office-online-for-the-web] Данный пакет самый распространенный среди всех аналогичных программ. Он является условно бесплатным (с пробным периодом), но, чаще всего, в учебных заведениях уже оформлена подписка на базовый набор инструментов (Excel, Word, PowerPoint, OneDrive). Однако, в случае её отсутствия все эти инструменты есть в формате веб-приложений с бесплатным и неограниченным доступом для зарегистрированных пользователей.

2. Сервисы Google Данная компания предоставляет бесплатный неограниченный доступ для зарегистрированных пользователей (Презентации, Документы, Таблицы, Диск и др.). Также присутствуют приложения для мобильных устройств.

3. LibreOffice [https://www.libreoffice.org/ download/download/?lang=ru] Данный пакет приложений является встроенным для операционных систем Linux, а также является бесплатным для других операционных систем.

\section{Вихеозвонки, конференции}

При организации дистанционного обучения нельзя обойтись без видеосвязи. Этой возможностью обладают как специализированные приложения, так и социальные сети (Вконтакте и Телеграм). Подробнее остановимся на приложениях:

1. ZOOM [https://zoom.us/] Облачная платформа для видеоконференций, веб-конференций, вебинаров, унифицированных коммуникаций. Бесплатный только 
ограниченный функционал.

2. Microsoft Teams [https://www.microsoft.com/ruru/microsoft-teams/group-chat-software] Групповой чат для Office 365. Позволяет создавать группы/комнаты, обмениваться файлами с коллегами. Тесная интеграция с Microsoft приложениями - Excel, Word, OneDrive, Power Point.

3. Google Meet [https://hangouts.google.com/] Cepвис состоит из приложений Мeеt (для групповой видеосвязи) и Chat (для создания групповых чатов). Работает на мобильных платформах. Бесплатный, но нужен аккаунт Google.
4. Яндекс.Телемост [https://telemost.yandex.ru/] Бесплатный сервис групповых видеозвонков в браузере. Не требует регистрации. Пользователи могут делиться экраном с другими, а также при необходимости отключать камеру и микрофон как на смартфоне, так и на мобильном устройстве.

В заключении хочется отметить, что вышеперечисленные сервисы могут быть интегрированы педагогами в образовательный процесс, однако, их не нужно рассматривать как полную замену очного образования. Лучше всего их использовать в качестве дополнения к традиционной форме обучения, комбинируя их между собой.

\section{ЛИТЕРАТУРА}

1. Аспицкая А.Ф. Использование информационно-коммуникационных технологий при обучении химии. Методическое пособие / А.Ф. Аспицкая. М.: Бином. Лаборатория знаний, 2019. - 177 с.

2. Калувэ Л. де, Маркс Э. Развитие школы. Модели и изменения / Л. де Калувэ, Маркс Э., М. Петри. - М.: Калужская типография стандартов, 2019. - 240 с.

3. Крук Б.И. Использование видео в дистанционном обучении. Для преподавателей и учителей. Издание второе / Б.И. Крук. - М.: Издательские решения, 2017. - $184 \mathrm{c}$.

4. Никуличева Н.А. Дистанционное обучение в образовании: организация и реализация / Н.А. Никуличева. - M.: LAP Lambert Academic Publishing, 2020. 220 c.

5. Русаков А.С. Образование и образы будущего. Школа перед эпохой перемен / А.С. Русаков - М.: Образовательные проекты, 2018. - 203 с.

6. Приказ Минобрнауки России от 12 мая 2020 г. № 1897 «0б утверждении и введении федерального государственного образовательного стандарта основного общего образования». [Электронный ресурс] URL: http://www.consultant.ru/document/cons_doc_LAW_353267/ (Дата 0бращения 11.12.2020)

( ) Нелюбина Елена Георгиевна (nelubina.elena@pgsga.ru), Ульянова Яна Александровна (ulyanova.yana@sgspu.ru), Минаков Дмитрий Александрович (minakov.dmitriy@sgspu.ru), Говоров Алексей Андреевич (govorov.aleksey@sgspu.ru). Журнал «Современная наука: актуальные проблемы теории и практики» 